\title{
Benign Ear Neoplasm
}

National Cancer Institute

\section{Source}

National Cancer Institute. Benign Ear Neoplasm. NCI Thesaurus. Code C8417.

A non-metastasizing neoplasm that arises from the external, middle, or internal ear.

Representative examples include ceruminous adenoma, polyp, and lipoma. 